\title{
Social Media Promotional Tools in Academic Library
}

\author{
A'dillah Mustafa, Intan Nurbaizura Zainuddin, Sufy Rabea Adawiya Idris, and Muhamad Faizal Abd \\ Aziz
}

\begin{abstract}
The web 2.0 applications such as Facebook and Twitter have been widely used by academic library as a new communication channel to gain the user feedback and insight towards their services and activities. This paper discussed the effectiveness of these two applications; Facebook and Twitter in promoting library services in one academic library with the research university status in Malaysia. This study reported the pilot study of the main research entitled "The effectiveness of Web 2.0 application in promoting library services in Malaysian research university libraries. The objectives of this study are: i) to identify the effect of these two applications in promoting the library services, and; ii) to identify the elements in Facebook and Twitter in promoting the library activities. The research question guiding this study are as follows; i) how frequent library Facebook and Twitter are used? And ii) What are the purpose of using Facebook and Twitter with the students? This study used quantitative method by using a questionnaire survey distributed to 50 students in one of the university libraries. The analysis is done thru simple Microsoft Excel to identify the percentage value. The findings indicated that Facebook provides the greatest impact as promotional tools, disseminating information, medium in answering user inquiries and provides instant feedback on the promotional initiatives. Finding in the elements in promoting found that forum and discussion are the most effective elements in Facebook. On the question of the purpose of using, information, communication is the most popular purpose in both applications. These research findings are useful to libraries and librarians in studying the impact gained by the libraries after embarking these two applications. This study also recommended that enhancement of library website design will provide better user experience in awareness of services and activities.
\end{abstract}

Index Terms-Web2.0, academic library, digital library, library promotional tools.

\section{INTRODUCTION}

Libraries in this millennium face an extraordinary challenge in servicing the millennial users. This fact was supported by the rapid development in information communication technologies (ICT) software and gadgets that very synonym to this user group. The millennium waves have a significant impact to libraries and librarians in providing the best possible services and activities to their users, specifically to this new millennial. Library promotional initiatives should go beyond the normal boundary. Library services and activities should be reachable after the normal opening hours. Libraries were first being introduced to Web 1.0 when the

Manuscript received September 26, 2014; revised February 11, 2015.

Adillah Mustafa, Intan Nurbaizura Zainudin, Sufy Rabea Adawiya, and Muhamad Faizal Abdul Aziz are with the Faculty of information Management Universiti Teknologi MARA Shah Alam, Malaysia (e-mail: a'dillah973@salam.uitm.edu.my, intannurbaizura@palam.uitm.edu.my, fy_idris@yahoo.com,mfaizal@um.edu.my).
World Wide Web becomes a necessity in every library. Web 1.0 is a static web without interactive content, only pages connected by hyperlinks. [1] stated that web 1.0 can be considered as read-only web and also a system of cognition. While, Web 2.0 technology offers user with more control of, the content, more interaction, flexible web design and collaborative content creation of the web. [2] observed that Web 2.0 are the new media that needed by the web generation, where the user interface are designed to engage the users in the library content. Web 2.0 offers more connectivity and opportunities to the user to contribute and participate to the library services and activities.

\section{BACKGROUNDS}

Academic libraries in Malaysia committed in fulfilling their function in depositing published information and disseminating knowledge to the students, academicians, researchers and staffs through services and activities conducted. This common understanding of the academic library function also agreed by [3] where they suggested library should be an enabler and facilitating the exchange and growth of information, knowledge and growth among the academic environment. In line with the development of ICT and web technologies, academic libraries took a significant step in promoting their services and activities by enhancing the library website from Web 1.0 to Web 2.0. [4] also found that Web 2.0 applications are able to promote participatory networking between librarians and user, where communication, collaboration and generating content are made possible. This study focus on two web 2.0 application which are used as a library promotional tool. The study by [5] reveals that as of November 2011, 14 academic libraries in Malaysia have Facebook application at their library website. Facebook was first found at the Universiti Malaya library in 2008, followed by 4 libraries in 2009 and 9 others in 2010 . This study is to understand the promotional function and elements available in Facebook and Twitter. As web 2.0 applications such as Facebook and Twitter have been widely used by academic library as early as in 2009 and also recognized as a new communication channel to gain the user feedback and insight towards their services and activities. This study aims to investigate Facebook and Twitter functions as a promotional tools. The objectives of this study are: i) to identify the effect of these two applications in promoting the library services, and ; ii) to identify the elements in Facebook and Twitter in promoting the library activities. The research question guiding this study are as follows; i) how frequent the library Facebook and Twitter are used? and ii) What are the purpose of using library Facebook and Twitter by the students?. The Scope of this research is specifically focused 
to Facebook and Twitter.

\section{LITERATURE REVIEW}

Promoting and marketing of library in the 21 st century has to go beyond the capabilities of the generic efforts. The millennial or net generations are looking towards more personalize services and opportunity to contribute to the event or activities. The advancement in technology and the World Wide Web (www) have offered an outstanding application to cater to the needs of these generations of users. [6] described www technology as techno-social system that making human interaction possible within the technological networks. Which cognition and precognition are required for human communication through technological atmosphere.

\section{A. Evolution of Web Technology in Llibrary}

As a dynamic entity, library has to be persisted to changes in the technological aspect. The library also has to move towards user-centric applications rather than user interaction applications only. [7] stated that web 1.0 is just an interaction technology, while web 2.0 is a user participation technology. [8] added that web 3.0 will enrich users with more browsing experience. While [9] introduce a web evolution with the description of the stages; Web 1.0: Reading (Traditional stage), Web 2.0: Writing and generation of contents (social web), Web 3.0: Machine understandable (Semantic Web), and Web 4.0: Intelligence and reasoner (Intelligent Web).

\section{B. Social Media in Library}

Social media have entered library as early as Tim Berners-Lee introduces www in early 1990s. A social networking service is any website or application that defined by [10] as focuses on connecting its users. These connections are often based on shared interests, activities, or real-life relationships. Users are typically single individuals, though businesses, organizations, and public figures are often represented on social networks. Where the first web generation Web 1.0 offers Website as one of its applications. Today, social media are in the interest of every library over the globe. National Library of Australia in the Social Media Strategy 2013-2014 [11] acknowledge the roles of social media in achieving library effectiveness and efficiency. They also acknowledge its vital roles in achieving the library, overall strategic goals. In the same report, National Library of Australia highlighted the benefits of having Facebook and Twitter in five areas; which are, i) Generate awareness of services, collections and activities, ii) Reputation management and brand strengthening, iii) Build relationship through engagement, iv) Research and user insight ;and v) Customer support. [12] from the Association of College and Research Libraries (ACRL) reported that Facebook is one of the important Social Networking Site (SNS) that affecting academic library now and in near future.

\section{Promoting Library Services}

Generally, library promotional efforts are the initiative in making the users aware of the current library update and development. [13] stated that promotion of library services and activities should include specific methods such as Web
2.0 applications. A Similar study by [14] also indicated that Web 2.0 are actively used in library promotion in Pakistan libraries. Further research on the effectiveness of Web 2.0 application are done by [15] and [16] in which, they reported that marketing through Facebook group are among the top ranking in promoting online databases. [17] reported another application of the social media which is Blogs are also identified as an effective promotional tools. Web 2.0 is also identified be interrelated with Marketing 2.0 as web element is taken to the marketing concept. [18] and [5] shared thier view as most of Malaysian academic libraries use a Facebook page as a marketing tool. In a professional view [19] reported Web 2.0 had a significant impact on the nature of the profession of information professional and operations of information agencies in Australian academic libraries.

\section{Definition of Web 2.0}

Web 2.0 holds different meaning depend on the context of discussion. Technologies, business and academia come with their very own definition. According to the technologies, [20], Web 2.0 is an advanced online collaborations and communication application. As in [21] is a new generation of website and web services that capitalize on the collaborations of the users. In the business environment, [22] seen web 2.0 as as interactive technology to capture the customer needs and to gather their opinion and support. In general, [23] defined as a set of economic, social and technology trends that collectively form the basis for the next internet generation. In a comparative study of web technology, [24] categorized twenty Web 2.0 website types that would be useful for information professional, which are: Audio, Chats, E-commerce, Games, Mashups, BlogPod, Collaboration, E-learning, Images, Multi-media, Blogging, Communication, E-mail, Knowledge Base, Portals, Bookmarking, Community, Filesharing, Lists, RSS, Calendars, CRM, Forum, Mapping and Wiki.

\section{E. Elements of Facebook and Twitter}

Facebook and Twitter offered a new channel in getting connected to others. [25] This is the undeniable fact that brings Malaysia to the number 18 in world ranking in Facebook account with the total of 13, 589,520 accounts as December 31, 2012. (Socialbakers.com, 2012). The account holder demographic shows that age group 18-32 and 25-34 holds the same percentage of $32.7 \%$. This age group is the millennial or net generation. Historically, Facebook is reported to be introduce in February 2004 by the Harvard university students, while Twitter in 2008.

\section{RESEARCH METHODOLOGY}

This is a quantitative study using simple survey questions to answer to the research question and research objective. The questionnaire are divided onto 2 parts, which Part $\mathrm{A}$ is on the demographic questions and Bart B on the Facebook and Twitter usage, elements and applications. Likert-scale and closed ended questions are used. The questionnaire are distributed to 50 users entering the university library during 2013 (January-May) academic year. 


\section{CONCEPTUAL FRAMEWORK}

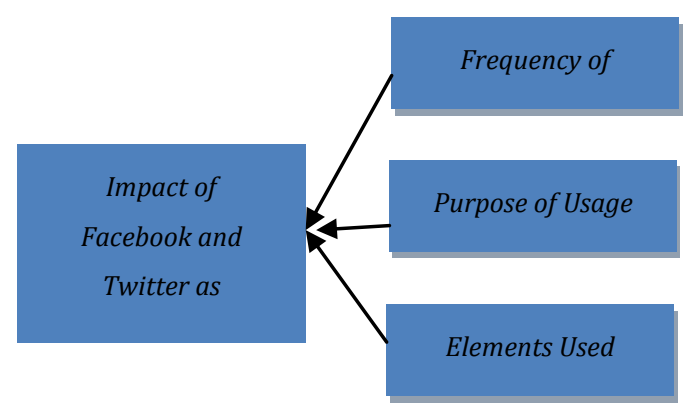

Fig. 1. Conceptual framework.

Fig. 1 describes the conceptual framework of this study, the Independent variables are Frequency of usage, Purpose of usage and Element used which will give impact to the Dependent variable which is Impact of Facebook and Twitter as promotional tools. Frequency of Usage refers to the number of visits to the applications in a month, Purpose of usage refers to reason for visiting the applications and Elements used refers to types of facilities and features used in the applications. These three variables will provide a direct indication on the impact of these applications as a promotional tools.

\section{FINDINGS}

This study provides 12 findings. 4 on the demographic, 6 on the usage, 4 for the purpose of used. The demographic data for program enrolled 43 respondents $(86 \%)$ from Bachelor degree followed by 6 respondents (12\%) Master Degree and only 1 respondents (2\%) $\mathrm{PhD}$.

\begin{tabular}{|c|c|c|}
\hline Program & No of Respondents & $\%$ \\
\hline Bachelor & 43 & 86 \\
\hline Master & 6 & 12 \\
\hline $\mathrm{PhD}$ & 1 & 2 \\
\hline \multicolumn{3}{|c|}{ TABLE II : FIELD OF STUDY } \\
\hline Field & No of Respo & $\%$ \\
\hline $\begin{array}{l}\text { Art and Social } \\
\text { Science }\end{array}$ & 13 & 26 \\
\hline Engineering & 12 & 24 \\
\hline Science & 15 & 30 \\
\hline Education & 3 & 6 \\
\hline Law & 2 & 4 \\
\hline Dentistry & 2 & 4 \\
\hline Medicine & 1 & 2 \\
\hline Economic & 1 & 1 \\
\hline Administration & 1 & 1 \\
\hline
\end{tabular}

For Field of Study, 13 respondents (26\%) are from Art and Social Science, 12 (24\%) from Engineering, 15 (30\%) from Science, $3(6 \%)$ from Education, Law and Dentistry both 2 respondents (4\%) and finally Medcine, Economic and Administration with 1 respondents each (3\%).

\begin{tabular}{lll}
\multicolumn{3}{c}{ TABLE III: DO You KNOW WHAT IS WEB 2.0? } \\
\hline Do you know & No of respondent & $\%$ \\
Yes & 30 & 60 \\
No & 20 & 40 \\
\hline
\end{tabular}

On the understanding of Web $2.0,60 \%$ or 30 respondents answer "Yes"they know what is Web 2.0, and only 20 respondents (40\%) answer "No".

\begin{tabular}{lll}
\multicolumn{3}{c}{ TABLE IV : FAMILIAR WITH WEB 2.0 } \\
\hline Familiar & No of Respondents & $\%$ \\
Yes & 31 & 62 \\
No & 11 & 22 \\
Uncertain & 8 & 16 \\
\hline
\end{tabular}

On Web 2.0 familiarity, 31 respondents $(62 \%)$ are familiar, while 11 respondents $(22 \%)$ are not familiar and only 8 respondents (16\%) are uncertain of the Web 2.0.

\section{ANALYSIS}

Research Objective 1: To identify the effect of these two applications in promoting the library services.

\begin{tabular}{|c|c|c|}
\hline Web 2.0 applications & No of Respondents & $\%$ \\
\hline Facebook & 10 & 54 \\
\hline Twitter & 5 & 26 \\
\hline Blogs & 1 & 5 \\
\hline YouTube & 2 & 10 \\
\hline RSS & 1 & 5 \\
\hline
\end{tabular}

Table V describes the Web 2.0 application that affected the students interest and awareness on library activities and services. Facebook are found to be providing a very huge affect with 10 respondents which carried $54 \%$, followed by Twitter that provide significant affect with 5 respondents which carried 26\%. Other applications such as Blogs, YouTube and RSS provide less affect with 4 respondents and carried $20 \%$ of overall percentage. This finding contrast with [9] on services for academic libraries in new era, which reported that only 38\% users used Facebook, while for Twitter hold $44 \%$. For Blogs, [26] found that $42.4 \%$ users choose Blogs to be the most effective application.

Research Objective 2: To identify the most effective elements in Facebook and Twitter used in promoting the library activities and services.

\begin{tabular}{lll} 
TABLE VI : MOST EFFECTIVE ELEMENTS IN FACEBOOK AND TWITTER \\
\hline Elements of Facebook and Twitter & Frequency & $\%$ \\
Chatting & 8 & 14 \\
User Tagging & 7 & 12 \\
User Comments & 7 & 12 \\
Photo Sharing & 9 & 16 \\
Group forum/Discussion & 15 & 27 \\
News Feed & 10 & 18 \\
\hline
\end{tabular}

Table VI described the most effective elements rated by the respondent that are affective in promoting library activities and services to them. Group forum /Discussion is the most effective elements with the frequency $15,(27 \%)$, followed by Photo sharing, $9(16 \%)$, Chatting $8(14 \%)$ and the least effective elements are User tagging and User comments with $7(12 \%)$. This finding contrast with [26] on social media in American libraries as public relations tools, found that Photo Sharing is the most effective elements.

Research question 1: How frequent library Facebook and Twitter are used in getting library update on activities and 
services?

\begin{tabular}{lllll}
\multicolumn{4}{c}{ TABLE VII: FREQUENCY OF USE } \\
\hline Frequency & \multicolumn{1}{c}{ Facebook } & \multicolumn{1}{c}{ Twitter } \\
& No of Respondents & No of Respondents & $\%$ \\
Everyday & 13 & 5 & \\
Once a Week & 9 & 8 & \\
Twice a Week & 12 & 14 \\
Once in Two & 4 & 4 \\
Week & & 19 \\
Once a Month & 12 & \\
\hline
\end{tabular}

Table VII shows the frequency of usage for both Facebook and Twitter. The majority of Facebook users 13 respondents and 5 Twitter users used them daily. 12 Facebook users and 19 Twitter users used them Once a Month. Followed by Twice a Week with 12 Facebook users and 14 Twitter users. 9 Facebook users and 8 Twitter users used them Once a Week. Lastly, only 4 Facebook users and 4 Twitter users used them Once in Two Weeks. This finding is found in relevant/ significant/related to [5] where he reported that academic libraries update their Facebook page status daily.

Research Question 2: What is the purpose of using library Facebook and Twitter by the students?

\begin{tabular}{lll} 
TABLE VIII: MAIN PURPOSE OF USING LIBARY FACEBOOK AND TWITTER \\
\hline Reasons & No of Respondents & $\%$ \\
Information & 30 & 60 \\
Communication & & 30 \\
Socialization & 15 & 6 \\
Make friends & 3 & 4 \\
Create awareness & 2 & \\
\hline
\end{tabular}

Table VIII describes the main purpose of using library Facebook and Twitter by the respondents. Majority or 30 respondents which carried $60 \%$ used the applications for Information Communication. Socialization came second with 15 respondents or $30 \%$. Followed by Make Friends with 3 respondents or $6 \%$ and the least respondents with only 2 or $4 \%$ used to Create awareness. This finding is similar to [27] on her study of Facebook addiction reported that Facebook operates primarily as a communication tool for female Malaysian students. She also reported that sending messages and information sharing are among the top reason.

\section{DISCUSSION}

Based on the findings, there are two main issues to be highlighted.

\section{A. Promotional Tools}

Facebook are found to be the most effective tools in promoting library activities and services. This is due to the number of respondents used Facebook more regular compared to other applications. Academic libraries should focus on creating a library Facebook and provide updates on their activities and services on a daily basis because real time information through Facebook and Twitter have affected their awareness.

\section{B. Two Way Communication and Instant Feedback}

Facebook and Twitter are among the Web 2.0 applications, developing to provide two way communication between librarians and users. Most of the respondents agreed Group forum/Discussion is a effective channel for communicating. In this matter, librarians must play a proactive role in providing feedback to user's inquiries.

\section{CONCLUSION}

Based on the findings, Facebook and Twitter have fully impacted the library promotional initiatives. Facebook is among the popular applications by students in getting and of sharing, Channel of socialization and also a medium for Making new friends. Even though Twitter are ranked second, it has also played a significant role in providing News feed and Photo Sharing. Therefore, academic library should use this application to promote other information such as digital repositories and Reference Services. In terms of variations of information, library Facebook should expand their scope to other academic information throughout the university. Although the data collected is limited, the finding has determined the Web 2.0 application do effected the library promotional initiatives.

\section{ACKNOWLEDGEMENT}

This research paper is sponsored by the Faculty of Information Management UITM and Research Management Institute (RMI) UITM under RIF Grant (RMI/RIF-540).

\section{REFERENCES}

[1] G. Brain. (April 2007). Basic definitions: Web 1.0, Web 2.0, Web 3.0. [Online]. Available: http://www.practicalecommerce.com/articles/464-Basic-DefinitionsWeb-1-0-Web-2-0-Web-3-0

[2] T. Sadeh, User experience in the library: A case study, New Library World, vol. 109, no. 1/2, pp. 7-24, 2008.

[3] M. Tripathi et al., "Use of Web 2.0 tools in academic libraries: A reconnaissance of the international landscape," The International Information \& Library Review, vol. 42, no. 3, pp. 195-207, December 2010 .

[4] W. W. K. Chua and A. E. S. Goh, "Techniques for discovering correspondences between ontologies," International Journal of Web and Grid Services, vol. 6, no. 3, pp. 213-243, September 2010.

[5] A. R. R. Ayu and A. Abrizah, "Do you facebook? Usage and applications of Facebook page among academic libraries in Malaysia," The International Information \& Library Review, vol. 43, no. 4, pp. 239-249, December 2011.

[6] C. Fuchs, "StudiVZ: Social networking sites in the surveillance society," Ethics and Information Technology, vol. 12, no. 2, pp. 171-185, 2010.

[7] M. Benioff. (August 2008). Welcome to Web 3.0: Now your other computer is a data center. [Online]. Available: http://techcrunch.com/2008/08/01/welcome-to-web-30-now-your-oth er-computer-is-a-data-center

[8] J. B. Singer. "The role and regulations for technology in social work practice and e-therapy: Social work 2.0.," in Social Workers' Desk Reference, A. R. Roberts, Ed. New York, U.S.A.: Oxford University Press, ch. 23, pp. 186-193.

[9] D. Consoli, "A model to extract sentimental knowledge in a semantic web context," The Journal of Knowledge Economy \& Knowledge Management, vol. 7, pp. 1-19, Spring 2012.

[10] Inc Paychex. (2012). Social Media 101: An introduction to facebook, twitter, linkedin, and beyond. [Online]. Available: http://www.buildmybiz.com/wp-content/uploads/2012/10/SocialMedi a101.pdf

[11] National Library of Australia. (March 2013). Social media strategy 2013-2014. [Online]. Available: http://www.nla.gov.au/policy-and-planning/social-media-strategy-201 3 
[12] A.C.R.I. Research Planning Review Committee, "2010 top ten trends in academic libraries: A review of the current literature," College \& Research Libraries News, vol. 71, no. 6, pp. 286-292, 2010.

[13] M. Dugan, "Database of the week: successfully promoting business database to faculty," Journal of Business \& Finance Librarianship, vol. 16, no. 2, pp. 159-170, 2011.

[14] S. Khan and R. Bhatti, "Application of social media in marketing of library and information services: A case study from Pakista," Webology, vol. 9, no. 1, pp. 1-13, 2012.

[15] L. Von Retzlaff, "E-commerce for library promotion and sustainability: How library technicians can market themselves and their library's services online," Australian Library Journal, vol. 55, no. 2, pp. 102-130, May 2006.

[16] Z. D. Xia, "Marketing library services through Facebook groups," Library Management, vol. 30, no. 67, pp. 469-478, 2009.

[17] A. Kaushik and J. Arora, "Blogs on marketing library services," DOSIDOC Journal of Library \& Information Technology, vol. 32, no. 2, pp. 186-192, 2012.

[18] D. Consoli, "Analysis of use of web 2.0 technology in small and medium companies to imlement enterprise 2.0 model," Ekonomika ir Vadyba: Aktualijos ir Perspektyvos, vol. 4, no. 20, pp. 13-20, 2010.

[19] Z. Yi, "Australian academic librarians' perceptions of effective web 2.0 tools used to market services and resources," The Journal of Academic Librarianship, vol. 40. pp. 220-227, 2014.

[20] A. Aldhaheri and C. Bach, "How to implement Marketing 2.0 Successfully," International Journal of Business and Social Science, vol. 4, no. 10, August 2013.

[21] S. Parise and P. J. Guinan, "Marketing using web 2.0." in Proc. 41st Annu. Hawaii International Conference on System Science, Hawaii, 2008, pp. 281-285.

[22] D. Consoli, "Analysis of use of web 2.0 technology in small and medium companies to implement enterprise 2.0 model," Ekonomika ir Vadyba: Aktualijos ir Perspektyvos, vol. 4, no. 20, pp. 13-20, 2010.

[23] J. Musser and T. O'Reilly, Web 2.0: Principles and Best Practices, Sebastopol, CA.: O’Reilly Media, 2007.

[24] Socialbakers.com. (2012). Malaysia Facebook statistics. [Online]. Available: http://www.socialbakers.com/facebook-statistics/malaysia

[25] M. Gerolimos and R. Konsta. (July 2011). Services for Academic libraries in the new era. D-Lib Magazine. [Online]. 17(7/8). Available: http://mirror.dlib.org/dlib/july11/gerolimos/07gerolimos.html

[26] C. R. Rogers. (May 2009). Social media, libraries, and Web 2.0: How American Libraries are using new tools for public relations and to attract new users. [Online]. Available: http://www.opus-bayern.de/bib-info/volltexte/2009/673/pdf/socialme diaandlibariesfinal-090523180527-phpapp02.pdf

[27] S. Sofiah, S. Z. Omar, J. Bolong, and M. N. Osman. (2011). Facebook addiction among female university students. The Public
Administration and Social Policies Review. [Online]. 7. Available: http://revad.uvvg.ro/files/nr7/10.\%20sharifah.pdf

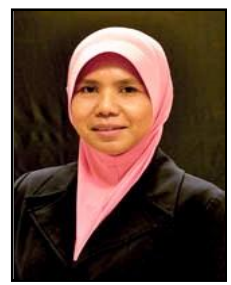

A'dillah Mustafa holds a master degree in information management from Universiti Teknologi MARA (UITM), Shah Alam, Selangor, Malaysia A in 2001. She is currently servicing in the Faculty of Information Management in the Department of Library Management, UITM Shah Alam. Her research areas are in e-books, secial networking site, social media and electronic contents.

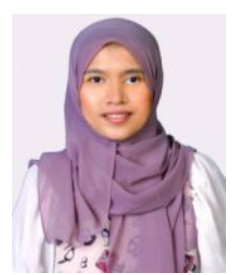

Intan Nurbaizura Zainuddin was born in 1985 in Negeri Sembilan, Malaysia. She is currently a lecture in the Faculty of Information Management in Universiti Teknologi MARA (UiTM) Malaysia.

She received her master degree in Library Science (MLS) Universiti Teknologi MARA Malaysia. Her study areas are in organization of knowledge (cataloging \& classification; abstracting \& indexing).

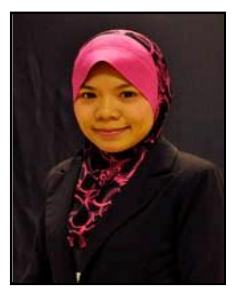

Sufy Rabea Adawiya Idris holds a master degree of science library \& information science from Internation Islamic University Malaysia, Gombak, Malaysia. She is currently servicing in the Faculty of Information Management, Department of Library Management, UITM Shah Alam. Her research areas are in organization of information, social media and information literacy.

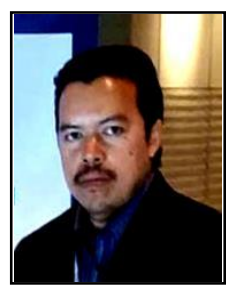

Muhamad Faizal Abd Aziz holds a master degree of information management from Manscher Metropolitan University, United Kingdom. He is currently servicing in the University Malaya Library as a librarian since 2000 until present. His research areas are in Web 2.0, social networking site, social media Apps. and institutional repository. 